\title{
Неизменный лидер
}

\author{
The constant leader
}

Арустамов С.С., Соколов В.С., Кокоев Н.Ш.

\section{Аннотация}

ЗАО «Куликово» - одно из крупнейших хозяйств России, где занимаются выращиванием овощей и картофеля. Кроме того, это еще и основной стратегический партнер по испытанию и внедрению в производство селекционных достижений Агрохолдинга «Поиск». Посевную кампанию в хозяйстве в 2019 году завершили в лучшие агротехнические сроки, но в связи с тем, что в мае месяце не было дождей, почвенная влага ушла быстро и были большие проблемы со всходами у мелкосемянных с.-х. культур (столовая свекла и морковь). В 2019 году было посажено 684 га картофеля, 307 га капусты, посеяно 310 га моркови, 224 га столовой свеклы. Всего валовой сбор этих овощных культур составил - 79183 т. Особенно благоприятен 2019 год был для капусты и картофеля. ЗАО «Куликово» по итогам года вошло в топ-5 хозяйств-лидеров Московской области по валовому сбору картофеля. В 2019 году площади посадки под отечественными гибридами овощей Агрохолдинга «Поиск» составляли 110 га, в том числе под столовой свеклой - 60 га, капустой - 40 га, под морковью - 10 га. Наилучшие результаты продемонстрировали гибриды капусты $F_{1}$ Герцогиня, $F_{1}$ Гарант, $F_{1}$ Континент, $F_{1}$ Застольный, $F_{1}$ Идиллия и $F_{1}$ Симпатия. Лучше всех из ранних гибридов показал себя гибрид $\mathrm{F}_{1}$ Симпатия его средняя урожайность была на уровне 50 т/га. Из поздних выделился гибрид $\mathrm{F}_{1}$ Герцогиня, средняя урожайность которого была 62 т/га. Из моркови наилучшие результаты показал гибрид $F_{1}$ Бейби, в свою очередь, из сортов свеклы столовой - Мулатка и Креолка, которые показали себя на уровне иностранных гибридов. Для ведения успешного агробизнеса в ЗАО «Куликово» построен крупный центр предпродажной подготовки овощной продукции. В него входят наземные и полуподземные хранилища, оборудованные современными системами вентиляции.

Ключевые слова: ЗАО «Куликово», овощеводство, картофелеводство, отечественные гибриды овощных культур, агробизнес.

Для цитирования: Арустамов С.С., Соколов В.С., Кокоев Н.Ш. Неизменный лидер // Картофель и овощи. 2020. №2. С. 16-19. https://doi.org/10.25630/PAV.2020.18.2.003

\author{
Arustamov S.S., Sokolov V.S., Kokoev N.Sh.
}

\section{Abstract}

CJSC Kulikovo is one of the largest farms in Russia, where they grow vegetables and potatoes. In addition, it is also the main strategic partner for testing and implementing the selection achievements of the Poisk agro holding into production. The sowing campaign in 2019 was completed in the best agrotechnical terms, but due to the fact that there was no rain in may, the soil moisture left quickly and there were big problems with seedlings of small-seeded agricultural crops (table beets and carrots). In 2019, 684 ha of potatoes, 307 ha of cabbage, 310 ha of carrots, and 224 ha of table beets were planted. In total, the gross harvest of these vegetable crops was 79183 tons. The year 2019 was especially favorable for cabbage and potatoes. At the end of the year, CJSC Kulikovo was included in the top 5 farms-leaders of the Moscow region in terms of gross potato harvest. In 2019, the area of planting under domestic hybrids of vegetables of the Poisk agro holding was 110 hectares, including under table beet -60 hectares, cabbage 40 hectares, under carrots - 10 hectares. the best results were demonstrated by hybrids of cabbage $F_{1}$ Gertsoginya, $F_{1}$ Garant, $F$, Continent, $F$, Zastolnyi, $F$ Idillia and $F$, Sympatia. Best of the early hybrids showed a hybrid $F_{1}$ Sympathy - the average yield was $50 \mathrm{t} / \mathrm{ha}$. Of late stood out $\mathrm{F}_{1}$ hybrid Gertsoginya, the average yield of which was $62 \mathrm{t} / \mathrm{ha}$. Carrots were the best performing $F_{1}$ hybrid Baby, in turn, of the varieties of beet - Mulatka and Kreolka, which showed itself on the level of foreign hybrids. To conduct successful agribusiness, CJSC Kulikovo has built a large center for pre-sale preparation of vegetable products. It includes ground and semi-underground storage facilities equipped with modern ventilation systems.

Key words: CJSC Kulikovo, vegetable growing, potato growing, domestic hybrids of vegetable crops, agribusiness.

For citing: Arustamov S.S., Sokolov V.S., Kokoev N.Sh. Constant leader. Potato and vegetables. 2020. No2. Pp. 16-19 (In Russ.). https://doi.org/10.25630/PAV.2020.18.2.003
3 АО «Куликово» - одно из крупнейших хозяйств России, расположенное в Дмитровском районе Московской области, где занимаются выращиванием овощей и картофеля. Кроме того, это еще и основной стратегический партнер по испытанию и внедрению в производство селекционных достижений Агрохолдинга «Поиск» $[1,2,3]$.

Цель: проанализировать и осветить итоги 2019 года в одном из наиболее успешных хозяйств России «ЗАО» Куликово.

Условия, материалы и методы исследований

При анализе использовали абстрактно-логический метод, включающий совокупность приемов индукции и дедукции, анализа и синтеза, аналогии, со- поставлений, системно-структурный анализ, методы формализации, моделирования, прогнозирования.

Результаты исследований

В 2019 году в «ЗАО» Куликово было посажено 684 га картофеля, 307 га капусты, посеяно 310 га моркови, 224 га столовой свеклы. Всего валовой сбор этих овощных культур составил - 79183 т.

С середины августа цех растениеводства ЗАО «Куликово» приступил к механизированной уборке продовольственного картофеля ранних сортов с площади в 15 га. В 2019 году агрономическая служба приняла решение попробовать ранний столовый сорт картофеля немецкой селекции Лаперла. Клубни Лаперлы овальнокруглые, покрыты желтой кожурой.
Сорт хорошо переносит засуху, быстро формирует урожай, отлично хранится, устойчив к болезням. По итогам года сорт показал отличную урожайность - около 46,0 т/га.

Посажено 38 гибридов капусты раннего, среднего и позднего сроков созревания. Упор сделан на сорта, устойчивые к киле. Валовой сбор этой культуры - 20572 т. Средняя урожайность капусты составила 67,0 т/га. Это единственная культура, при уборке которой применялся ручной труд. Остальные культуры убирались механизированным способом комбайнами немецкого концерна Grimme и датской компании Asa Lift. Всего в парке ЗАО «Куликово» 10 картофелеуборочных комбайнов Grimme различных модификаций. 
Не подвела в 2019 году и морковь. Убрано 18092 т этой культуры. Средняя урожайность моркови составила 58,0 т/га.

Ежедневно цех овощеводства реализовывал до 70 т капусты, до 40 т моркови, до 20 т столовой свеклы. Корнеплоды поставляли в столичные сетевые магазины (в основном в торговую сеть группы компаний X5 Retail) под торговой маркой «Куликово поле». Предварительно овощи проходили предпродажную подготовку: помывку, калибровку и сортировку. На упаковочных линиях корнеплоды упаковывались в полиэтиленовые мешки и сетки объемом от 1 до 25 кг. Собственное автотранспортное предприятие оказывало помощь в поставке овощей.

Наибольшие площади в хозяйстве занимал картофель. Валовый сбор картофеля составил 31087 т при средней урожайности 45,5 т/га. Наименьшие площади в 2019 году занимала столовая свекла. Валовый сбор этой культуры составил 9430 т при средней урожайности 42,0 т/га.

В 2019 году в хозяйстве приступили к очередному этапу масштабной программы мелиорации на площади 390 га. Для реализации этих сложных технических работ в ЗАО «Куликово» ранее был создан цех мелиорации. Подразделение возглавляет Александр Азаров. За последние десять лет введено в оборот около 2 тыс. га земель, из них 1 тыс. 200 га мелиорируемые. И это не предел. ЗАО «Куликово» достались тяжелые земли, которые ежегодно подтапливают весенние паводки. Некоторые участки имеют изношенные гидромелиоративные сооружения и каналы, поэтому программа мелиорации рассчитана на долгосрочную перспективу.

На протяжении последних десяти лет в ЗАО «Куликово» появилась целая линейка энергонасыщенных тракторов европейского и американского производства. Это высокопроизводительные и мощные американские тракторы John Deere, европейские Valtra, белорусские МТЗ 1221. В 2019 году на государственный технический осмотр ЗАО «Куликово» выставляло более 60 тракторов и прицепов. Помимо тракторов МТ3, John Deere, Valtra, «Кировец» инспекторы осмотрели также технику цеха мелиорации - английский дреноукладчик Mastenbroek, тяжелые болотные бульдозеры и экскаваторы [4]

Для ведения успешного агробизнеса в ЗАО «Куликово» в прошлом году был построен крупный центр предпродажной подготовки овощной продукции. В него входят наземные и полуподземные хранилища, оборудованные современными системами вентиляции. Картофель и столовую свеклу закладывают на длительное хранение навальным способом, а морковь и капусту - в контейнерах. Перед реализацией корнеплоды проходят тщательную предпродажную подготовку: помывку, калибровку и сортировку. Затем овощи поступают на упаковочные линии, где фасуются в различную тару: удобные в применении и хранении пакеты весом 1 кг и сетки весом от 2 до 25 кг. В центре предпродажной подготовки работают 13 упаковочных линий. Первые линии были приобретены предприятием еще в начале двухтысячных годов и до сих пор исправно работают. В этом большая заслуга начальника технического отдела Леонида Мамаева. Он работает в ЗАО «Куликово» с 2001 года и со своим коллективом готов устранить любую неисправность в оборудовании. Руководит производственным процессом в центре предпродажной подготовки заместитель генерального директора ЗАО «Куликово» Виктор Венедиктов.

Большая часть линий - импортного производства (немецкой компании Gillenkirch и итальянской SORMA). Есть и российская линия компании Лидер-Пак. Одна такая линия способна упаковать до 5 т корнеплодов за смену. В этом году ЗАО «Куликово» также закупило две новые упаковочные линии Минского экспериментального завода (Республика Беларусь). Инвестиции составили около 4 млн р. Уникальная конструкция бункеров и транспортеров белорусской линии позволяет до минимума снизить механические повреждения корнеплодов. Сегодня на одной из линий фасуются крупные клубни (более 300 г) сортов картофеля Бельмондо и Венди для столичных ресторанов. На других линиях, до их полноценного запуска, пока готовятся к продаже отборные партии овощей для ярмарок в Москве [5].

Каждый год бывает трудным посвоему, и прошлый - не исключение. Казалось бы, снега была много, но почва не была проморожена, и он растаял очень быстро. В связи с этим, посевную кампанию завершили в лучшие агротехнические сроки, но в связи с тем, что в мае месяце не было дождей, почвенная влага ушла быстро и были большие проблемы со всходами у мелкосемян- ных с.- х. культур (столовая свекла и морковь).

С начала июня в Московской области установилась аномально жаркая и сухая погода. Дневная температура превысила $30{ }^{\circ} \mathrm{C}$, почва из-за отсутствия осадков потрескалась. Всему виной - несколько антициклонов, не пускающих своим высоким давлением холодные воздушные массы. В первую очередь из-за дефицита влаги пострадали растения - слаборазвитая система корнеплодов и рассады капусты просто не могла забрать влагу из нижних слоев почвы. Не было влаги, не было и минеральных солей, которые так нужны для роста растений. В этот сложный период цех овощеводства ЗАО «Куликово» мобилизовал все силы и средства для организации круглосуточного полива. На полях были развернуты восемь комплектов систем орошения итальянской компании Idrofoglia. И самые негативные последствия антициклонов благодаря согласованной работе нашей агрономической службы удалось преодолеть.

Прошлый год можно по праву назвать капустным - теплая и сырая, прямо-таки «капустная» погода, благоприятно сказалась на урожайности этого традиционного для России овоща. Кроме того, свою роль сыграл и регулярный полив. Некоторые кочаны белокочанной капусты, выращенные в 2019 году, весили от 8 до 10 кг.

Также благоприятен 2019 год оказался и для картофеля, т.к. погодные условия позволили высадить его в прогретую почву в краткие агротехнические сроки, а значит, получить дружные всходы. Правда, в июне месяце наблюдалась нехватка влаги, но грамотные поливы и дождливый июль сделали свое дело - урожай «второго хлеба» по итогам года оказался отменным.

Несмотря на все сложности, в этом году ЗАО «Куликово» не сдало позиции и вошло в топ-5 хозяйствлидеров Московской области по валовому сбору картофеля. Таких высоких показателей в хозяйстве достигли, используя сразу несколько зарекомендовавших себя подходов. ЗАО «Куликово» каждый год на площади 65-70 га (около 10\% от общих посадок картофеля) постоянно проводит обновление семенного материала картофеля, закупает элитные семена из Германии, Голландии. На продовольственные цели высаживается только первая репродукция семян. Кроме того, мы используем научно обоснованное размещение по- 


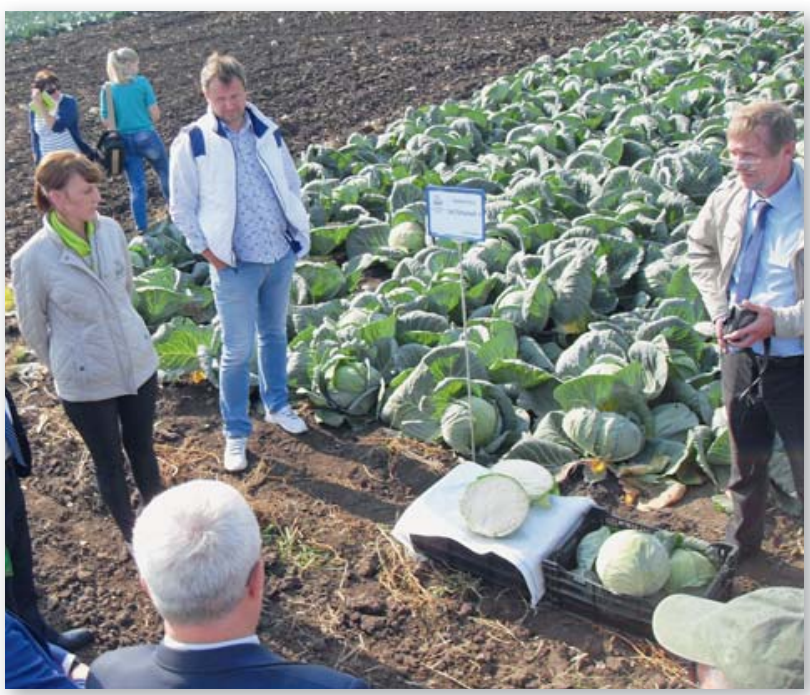

Селекционер Г.А. Костенко представляет гибрид $F$, Застольный на полях ЗАО «Куликово»

садок картофеля в севообороте, большое внимание уделяем защите картофеля от болезней. Не допускаем большого разрыва межу фунгицидными обработками картофеля против фитофтороза, альтернариоза и т.д. Обеспечиваем весь вегетационный период сбалансированное питание, т.е. оптимальное сочетание удобрений и некорневых подкормок с микроэлементами в доступной для растений форме [6].

Известно, что основа любой компании - специалисты. Их подбору мы уделяем особенное внимание. Наиболее тесно работаем с РГАУ-МСХА имени К.А. Тимирязева и Яхромским колледжем. Студенты последнего часто проходят практику в нашем хозяйстве. Сегодня у нас работает агроном из Республики
Мордовия, выпускник Мордовского государственного университета имени Н. П. Огарева. Одна наша сотрудница, агрономсеменовод, параллельно проходит обучение в аспирантуре РГАУ-МСХА имени К.А. Тимирязева. Однако кадровый голод все еще сохраняется. Если квалифицированными агрономами и технологами коллектив предприятия более или менее укомплектован, то механизаторов и разнорабочих для прополки, уборки капусты и предпродажной подготовки овощей и картофеля катастрофически не хватает. Сейчас нам также требуются такие специалисты, как технолог по хранению овощей и картофеля, в цех реализации требуются специалисты среднего звена.

Можно отметить, что в последние годы студенты лучше знают теорию, чем практику, но без практики сейчас никуда. Нашим работникам, при необходимости, предоставляется общежитие, они полностью обеспечиваются питанием и необходимой спецодеждой. В хозяйстве всегда рады видеть грамотных дипломированных специалистов.

В связи с этим нельзя не сказать о том, что очень большой урон нанесен привлечению трудовых мигрантов для с. - х. работ тем, что было отменено отраслевое и региональное квотирование на въезд рабочих из республик СНГ, а вместо этого была введена система патентов, которые позволяют иммигрантам работать в любой сфере экономики РФ. Естественно, трудовые мигранты сместились из таких трудозатратных отраслей, как сельское хозяйство и строительство, в сферу торговли - на оптовые и розничные рынки, где имеют хождение большие потоки наличных денег. То есть, государство практически утратило свои регуляторные функции в об- ласти трудовой миграции, что очень сильно ударило по такому сегменту, как производство и продажа овощей, требующих больших трудозатрат.

В прошлом году площади посадки под отечественными гибридами овощей Агрохолдинга «Поиск» составляли 110 га, в том числе под столовой свеклой - 60 га, капустой - 40 га, под морковью - 10 га. В течение последних семи лет площади под отечественными гибридами неуклонно расширяются. Мы проводим испытания новых гибридов капусты в производственных условиях, более всего довольны такими гибридами Агрохолдинга «Поиск», как $F_{1}$ Герцогиня, $F_{1}$ Гарант, $F_{1}$ Континент, $F_{1}$ Застольный, $F_{1}$ Идиллия и $F_{1}$ Симпатия. Лучше всех из ранних показал себя гибрид $\mathrm{F}_{1}$ Симпатия - его средняя урожайность была на уровне 50 т/га. Из поздних, можно выделить гибрид $\mathrm{F}_{1}$ Герцогиня, средняя урожайность которого была 62 т/га. В текущем году площади только под этим гибридом будут расширены в два раза - до 20 га. Из моркови наилучшие результаты показал гибрид $\mathrm{F}_{1}$ Бейби. Очень довольны в хозяйстве сортами свеклы столовой Мулатка и Креолка, которые показали себя на уровне иностранных гибридов.

Технологии ЗАО «Куликово» уже сейчас позволяют получать одни из самых высоких урожаев овощных культур в России. Кроме того, в 2019 году ЗАО «Куликово» совместно с Агрохолдингом «Поиск» были изданы рекомендации по возделыванию ряда овощных культур (капуста, свекла, морковь и др.). Согласно данным агрономической службы ЗАО «Куликово», эти рекомендации уже сейчас однозначно востребованы у овощеводов Московской области. Но это только начало, и они постепенно начинают становиться «библией агрономов» в соседних областях, а также на юге России, где «Поиском» в этом плане была проделана колоссальная работа и работает собственный селекцентр. Кроме того, существенной разницы в технологиях выращивания отечественных и зарубежных гибридов нет. Можно лишь отметить, что некоторые устойчивые к определенным заболеваниям гибриды не требуют дополнительных фунгицидных обработок.

В последние годы в России набирает обороты органическое земледелие и заметен тренд на общую биологизацию сельского хозяйства. Агрохолдинг «Поиск» также начал работу по выстраиванию системных 


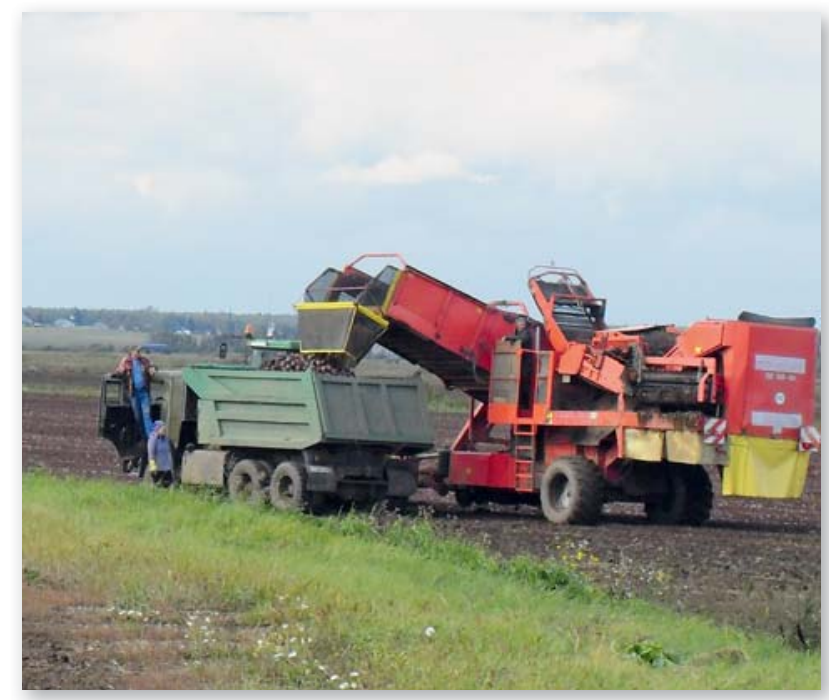

Уборка свеклы в ЗАО «Куликово»

связей с наукой и практикой в этой сфере. Биологизация сейчас активно внедряется в производство и можно предположить, что и в дальнейшем это направление будет лишь расширяться. Поэтому его нельзя списывать со счетов и уже сегодня нужно полагать, что через 5-10 лет существенная часть населения будет искать именно овощи, выращенные без использования агрохимикатов. А значит, эту нишу нужно занимать, и тот, кто это сделает первым, снимет все сливки, остальные же окажутся в роли догоняющих. Сейчас на почвах с высоким содержанием гумуса в хозяйстве планируется выращивать овощи без использования минеральных удобрений и с обработкой только биопрепаратами в связи с чем завязалось наше сотрудничество с Всероссийским НИИ биологической защиты растений (ВНИИБЗР). Это будет первый шаг ЗАО «Куликово» в сторону постепенного перехода к выращиванию органических или экологически чистых овощей. Но этот переход, конечно, будет не единомоментным, а постепенным.

Один из отрицательных моментов в функционировании хозяйства - постоянное повышение себестоимости нашей продукции, что связано с неизменным ростом тарифов на электроэнергию и коммунальные платежи, а также с ежегодным повышением цен на удобрения, средства защиты растений, запасные части к сельхозтехнике и автотранспорту, равно как и на саму технику, особенно импортного производства. Например, в 2019 году тарифы на электроэнергию повысились на 8\%, цена на топливо на 10-12\%, цена на гербициды на $6-7 \%$ и т.д. При этом цена на овощи и картофель упала, по сравнению с прошлым сезоном на 7-8\%, что практически уничтожило рентабельность отрасли. В то же время, овощи и картофель - социальный продукт, потребляемый всеми слоями населения, входящий в ценовую группу экономкласса не допускающую резкого скачка потребительских цен.

\section{Выводы}

После почти 20 лет развития ЗАО «Куликово» добилось наиболее высоких результатов выращивания овощных культур в России, из года в год занимая лидирующие позиции в этой сфере. Все это достигнуто согласованной работой всех служб хозяйства и грамотным подбором специалистов, которому уделено особое внимание. Сейчас ставится задача: улучшить качество овощной продукции и вывести на новый уровень ее сохранность в зимне-весенний период. В последние годы погодные условия стремительно меняются и стало сложнее сохранить овощи до апреля-мая, в связи с чем поставлена задача максимально оборудовать холодильными камерами все имеющиеся в хозяйстве хранилища. Кроме того, поддержан тренд на общую биологизацию выращивания овощей в хозяйстве.

\section{Библиографический список}

1.Литвинов С.С., Клименко Н.Н., Арустамов С.С. Селекция и семеноводство - основа возрождения товарного овощеводства в России // Картофель и овощи. 2012. №3. С. 2-4.

2.Ховрин А.Н., Кокоев Н.Ш. Стратегическое партнерство // Картофель и овощи. 2017. №11. С. 8-9.

З.Бутов И.С. День поля в ЗАО «Куликово» // Картофель и овощи. 2012. №8. С. 16-17.

4.Новости ЗАО «Куликово» за 2019 год [Электронный ресурс] URL: https://kulikovoagro.ru/2019.html. Дата обращения: 23.01.19.

5.Дмитровский округ в лидерах по сбору урожая картофеля [Электронный ресурс] URL: http://in-dmitrov.ru/novosti/ obschestvo/dmitrovskiy-okrug-v-liderah-po-sboru-urozhayakartofelya. Дата обращения: 23.01.19.

6.Секачев А.А., Жирнов А.В. Разработка мероприятий по повышению эффективности производства картофеля на ЗАО «Куликово» // Экономика и социум. 2015. №2-4. С. 267-271.

\section{References}

1.Litvinov S.S., Klimenko N.N., Arustamov S.S. Selection and seed production-the basis for the revival of commodity vegetable production in Russia. Potato and vegetables. 2012. №3. Pp. 2-4 (In Russ.).

2.Hovrin A.N., Kokoev N.Sh. Strategic partnership. Potato and vegetables. 2017. №11. Pp. 8-9 (In Russ.).

3.Butov I.S. Field day in CJSC Kulikovo. Potatoes and vegetables. 2012. №8. Pp. 16-17 (In Russ.).

4.News of CJSC Kulikovo for 2019 [Web resource] URL: https:// kulikovoagro.ru/2019.html. Date of access: 23.01.19 (In Russ.).

5.Dmitrov district in the leaders in potato harvest [Web resource] URL: http://in-dmitrov.ru/novosti/obschestvo/dmitrovskiy-okrug-vliderah-po-sboru-urozhaya-kartofelya. Date of access: 23.01.19 (In Russ.).

6.Sekachev A.A., Zhirnov A.V. Development of measures to improve the efficiency of potato production at CJSC «Kulikovo». Economy and society 2015. №2-4. Pp. 267-271 (In Russ.).

\section{Об авторах}

Арустамов Сергей Сергеевич, председатель Совета директоров ЗАО «Куликово». E-mail: kulikovo@list.ru

Соколов Василий Сергеевич, член Совета директоров ЗАО «Куликово». E-mail: kulikovo@list.ru

Кокоев Нугзар Шотаевич, главный агроном ЗАО «Куликово». E-mail: kulikovo@list.ru

\section{Author details}

Arustamov S.S., chairman of the Board of Directors of CJSC Kulikovo. E-mail: kulikovo@list.ru

Sokolov V.S., member of the Board of Directors of CJSC Kulikovo. E-mail: kulikovo@list.ru

Kokoev N.Sh., chief agronomist of CJSC Kulikovo. E-mail: kulikovo@list.ru 